une revue Gallia

Rhône-Alpes | 2007

\title{
La Rivière
}

Domaine départemental des Écouges, vallon de Fessole

\section{Alain Belmont}

\section{(2) OpenEdition \\ 12 Journals}

Édition électronique

URL : http://journals.openedition.org/adlfi/7145

ISSN : 2114-0502

Éditeur

Ministère de la culture

Référence électronique

Alain Belmont, «La Rivière », ADLFI. Archéologie de la France - Informations [En ligne], Rhône-Alpes, mis en ligne le 01 mars 2007, consulté le 03 mai 2019. URL : http://journals.openedition.org/adlfi/7145

Ce document a été généré automatiquement le 3 mai 2019.

(C) Ministère de la Culture et de la Communication, CNRS 


\title{
La Rivière
}

\author{
Domaine départemental des Écouges, vallon de Fessole
}

\section{Alain Belmont}

Identifiant de l'opération archéologique : 229453

Date de l'opération : 2007 (SD)

1 D'une surface totale de $34 \mathrm{~m}^{2}$, les sondages programmés menés en 2007 au vallon de Fessole visaient à déterminer la nature et la chronologie d'occupation d'une structure en pierres sèches implantée à près de $1300 \mathrm{~m}$ d'altitude dans la vallée des Ecouges, en partie nord du massif du Vercors et en lisière d'alpage et de forêt. Cette structure s'est avérée être une cabane de bûcherons des $\mathrm{XIX}^{\mathrm{e}} \mathrm{s}$. et $\mathrm{XX}^{\mathrm{e}} \mathrm{s}$., d'à peine $6 \mathrm{~m}$ sur $2 \mathrm{~m}$, construite en bois sur solin de pierre. Elle a succédé à une longue série de charbonnières et aussi à un entrepôt de charbons de bois d'au moins $6 \mathrm{~m}$ sur $4 \mathrm{~m}$, à structure de planches sur poteaux, construit entre la fin du XIV ${ }^{\mathrm{e}}$ s. et le début du XVI ${ }^{\mathrm{e}}$ s. (datation ${ }^{14} \mathrm{C}$ Archéolabs). Ce type d'entrepôt est bien attesté par la documentation écrite; il en existait tout un ensemble semé à travers la vallée, dans lesquels les nombreux charbonniers travaillant aux Ecouges stockaient les provisions de charbon de bois en attendant que des mulets, au rythme de 4000 par an au XVIII ${ }^{\mathrm{e}}$ s., viennent les chercher. Une fois chargés, les mulets descendaient alors le précieux combustible dans la vallée de l'Isère, où il alimentait la fonderie royale de canons de Saint-Gervais. Le mauvais état d'entretien des entrepôts et les difficiles conditions météorologiques provoquaient de fréquents effondrements des bâtiments et d'importantes pertes de combustible. Ces conditions expliquent probablement la présence sur le site de près de $0,70 \mathrm{~m}$ d'épaisseur de sédiments charbonneux, qui pourront nourrir d'éventuelles recherches anthracologiques ultérieures. Complétant un programme de prospections systématiques et plusieurs chantiers de fouilles programmées, la campagne 2007 aura ainsi révélé un type d'installation en milieu forestier - les étaux (entrepôts) - peu ou prou ignoré par la recherche. Elle témoigne aussi d'un développement de l'industrie charbonnière aux 
Ecouges antérieur d'au moins deux siècles à l'installation de la fonderie royale de SaintGervais, et qui a pu être contemporaine de la présence des Chartreux en ces lieux.

2 BELMONT Alain

INDEX

Index géographique : Rhône-Alpes, Isère, Rivière

Index chronologique : Bas Moyen Âge, XVIe siècle apr. J.-C., XVIIe siècle apr. J.-C., Temps

Modernes, XVIIIe siècle apr. J.-C.

operation sondage (SD)

\section{AUTEURS}

ALAIN BELMONT 